\title{
Unit per Square Meter per Minute
}

National Cancer Institute

\section{Source}

National Cancer Institute. Unit per Square Meter per Minute. NCI Thesaurus. Code C73785.

An arbitrary unit of substance rate expressed in unit(s) per square meter per period of time equal to sixty seconds. 